Editorial

\title{
Computational Approaches in Membrane Science and Engineering
}

\author{
Alessio Fuoco *(1), Giorgio De Luca, Elena Tocci $₫$ and Johannes Carolus Jansen $(\mathbb{B}$ \\ Institute on Membrane Technology, CNR-ITM, Via P. Bucci 17/C, 87036 Rende (CS), Italy; \\ g.deluca@itm.cnr.it (G.D.L.); e.tocci@itm.cnr.it (E.T.); johannescarolus.jansen@cnr.it (J.C.J.) \\ * Correspondence: a.fuoco@itm.cnr.it; Tel.: +39-0984-492008
}

Received: 17 April 2020; Accepted: 21 April 2020; Published: 23 April 2020

Computational modelling and simulation form a consolidated branch in the multidisciplinary field of membrane science and technology [1-4], covering a wide range of disciplines from chemistry, physics and materials science, to chemical engineering and process technology. This Special Issue aims to cover all the aspects of computer-aided investigations: from molecular modelling to assess the properties of the materials at the atomic scale, to fluid dynamics to investigate the membrane module performances, to novel characterization and data elaboration methods.

In this issue, Petrosino et al. [5] used a double-scale computational approach, based on quantum and molecular mechanics, to focus on the noncovalent interactions involved in the adsorption of enzymes on polymeric membrane surfaces. They investigate the surface charges of the enzyme and membrane at the sub-nano- and nano-scale, while a larger molecular mechanics model is used to study the surface protein interactions, and hence the adsorption. The potential energy profile of the enzyme shows good agreement with the experimental data. Such knowledge of the potential energy landscape is important for subsequent simulations. One of their main findings is the enzyme's orientation analysis as a function of its distance from the surface. This analysis is the first step to investigate the kinetics of immobilized enzymes. Finally, the quantities, computed without resorting to adjustable parameters, can be used as inputs in meso- or macroscale modeling.

Keshin and Altinkaya [6] review the atomic-molecular modelling used to predict several properties of mixed matrix membranes (MMMs) based on metal organic frameworks (MOFs) as the filler. They discuss the models that allow the screening of MOF/polymer compatibility as well as their combination to increase their transport properties for gas separation applications. In particular, they pointed out that the used force fields should be validated for the in-silico synthesis of novel materials and their transport properties' characterization.

Mazo et al. [7] use molecular dynamics to compare four glassy polymers, two with low permeability and high selectivity, the other two being highly permeable but with low selectivity. Their analysis of the relationship between molecular structures and their gas transport properties shows that the precise correlation between the latter depends on the free volume and free volume distribution. They also highlight the chemical nature of the groups forming the surface of free volume elements, identifying fluorine atoms as the dominant species.

Molecular dynamics simulations are also applied by Karataraki et al. [8] in their investigations on the interaction of water with conically shaped carbon nanoparticles. To increase the insight into the membrane-assisted separation processes in the liquid phase, their studies focus on the properties of the hydration shell of nanoparticles and on the behavior of water molecules in a nano-confined environment, a crucial aspect for the separation performances of membranes $[9,10]$. Thus, this work will help in the understanding of the extraordinary efficiency of biological porins [11,12].

Macroscopic computational approaches are used by Valdés et al. [13], who study fluid dynamics to investigate the behavior of supercritical $\mathrm{CO}_{2}$ in hollow fiber membrane modules used as contactors. 
The investigation of the 3D profiles describing the hydrodynamics of the supercritical fluid highlights the critical points in the process, providing useful information to anticipate potential technical issues, and helping with the future exploitation of this technology. Interestingly they show an inverse correlation between the number of fibers and the irregularity of the flow.

Also at the macroscopic scale, a combination of fluid dynamics and mechanical simulations is applied by Battaglia et al. [14] to investigate the effect of the transmembrane pressure in electro-membrane processes using round pillar type-profiled membranes. This study shows that the pressure that arises between the solutions flowing in alternate channels causes a slight deformation of the membrane, which may affect its mass transport properties. Thus, their computational work investigates these aspects for a better understanding of the membrane behaviour that normally remains hidden for the eye.

At a different level, computational tools are also used by Fuoco et al. [15] for a better comparison of the experimental data with theoretical transport models. For instance, they discuss two different methods for the analysis of the transient and pseudo-steady state gas transport in dense polymeric or mixed matrix membranes. They show some of the limits of the traditional time lag method in the description of complex systems such as mixed matrix membranes, and demonstrate how the fit of the entire permeation curve gives information on anomalies in the gas transport. In combination with a specially designed permeation instrument, this evaluation method provides even accurate mixed gas diffusion coefficients data, which are so far almost inaccessible.

In conclusion, the papers in this Special Issue illustrate how computational approaches, different in the "time-space scale", can be used at several levels in the field of membrane science and engineering. It shows how a more extensive use of computer-aided approaches contributes not only to strengthening the fundamental research in this field, but it also helps a more successful exploitation of membrane technology in industrial applications.

Finally, we are really grateful to all the authors for their valuable contributions and to the reviewers for their critical remarks and suggestions, which boosted the quality of the herein published scientific works.

Author Contributions: All authors contributed in similar extent to the manuscript. All authors have read and agreed to the published version of the manuscript.

Funding: This research received no external funding.

Conflicts of Interest: The authors declare no conflict of interest.

\section{References}

1. Liang, X.; Zhang, X.; Zhang, L.; Liu, L.; Du, J.; Zhu, X.; Ming Ng, K. Computer-Aided Polymer Design: Integrating Group Contribution and Molecular Dynamics. Ind. Eng. Chem. Res. 2019, 58, 15542-15552. [CrossRef]

2. Kupgan, G.; Abbott, L.J.; Hart, K.E.; Colina, C.M. Modeling Amorphous Microporous Polymers for $\mathrm{CO}_{2}$ Capture and Separations. Chem. Rev. 2018, 118, 5488-5538. [CrossRef] [PubMed]

3. Venable, R.M.; Krämer, A.; Pastor, R.W. Molecular Dynamics Simulations of Membrane Permeability. Chem. Rev. 2019, 119, 5954-5997. [CrossRef] [PubMed]

4. Xu, Q.; Jiang, J. Molecular simulations of liquid separations in polymer membranes. Curr. Opin. Chem. Eng. 2020, 28, 66-74. [CrossRef]

5. Petrosino, F.; Curcio, S.; Chakraborty, S.; De Luca, G. Enzyme Immobilization on Polymer Membranes: A Quantum and Molecular Mechanics Study. Computation 2019, 7, 56. [CrossRef]

6. Keskin, S.; Alsoy Altinkaya, S. A Review on Computational Modeling Tools for MOF-Based Mixed Matrix Membranes. Computation 2019, 7, 36. [CrossRef]

7. Mazo, M.; Balabaev, N.; Alentiev, A.; Strelnikov, I.; Yampolskii, Y. Structure and Properties of High and Low Free Volume Polymers Studied by Molecular Dynamics Simulation. Computation 2019, 7, 27. [CrossRef]

8. Karataraki, G.; Sapalidis, A.; Tocci, E.; Gotzias, A. Molecular Dynamics of Water Embedded Carbon Nanocones: Surface Waves Observation. Computation 2019, 7, 50. [CrossRef] 
9. Fuoco, A.; Galier, S.; Roux-de Balmann, H.; De Luca, G. Correlation between macroscopic sugar transfer and nanoscale interactions in cation exchange membranes. J. Membr. Sci. 2015, 493, 311-320. [CrossRef]

10. Fuoco, A.; Zwijnenberg, H.; Galier, S.; Balmann, H.R.; De Luca, G. Structural properties of cation exchange membranes: Characterization, electrolyte effect and solute transfer. J. Membr. Sci. 2016, 520, 45-53. [CrossRef]

11. Tunuguntla, R.H.; Henley, R.Y.; Yao, Y.-C.; Pham, T.A.; Wanunu, M.; Noy, A. Enhanced water permeability and tunable ion selectivity in subnanometer carbon nanotube porins. Science 2017, 357, 792-796. [CrossRef]

12. Wagh, P.; Escobar, I.C. Biomimetic and bioinspired membranes for water purification: A critical review and future directions. Environ. Prog. Sustain. Energy 2019, 38, e13215. [CrossRef]

13. Valdés, H.; Unda, K.; Saavedra, A. Numerical Simulation on Supercritical $\mathrm{CO}_{2}$ Fluid Dynamics in a Hollow Fiber Membrane Contactor. Computation 2019, 7, 8. [CrossRef]

14. Battaglia, G.; Gurreri, L.; Airò Farulla, G.; Cipollina, A.; Pirrotta, A.; Micale, G.; Ciofalo, M. Pressure-Induced Deformation of Pillar-Type Profiled Membranes and Its Effects on Flow and Mass Transfer. Computation 2019, 7, 32. [CrossRef]

15. Fuoco, A.; Monteleone, M.; Esposito, E.; Bruno, R.; Ferrando-Soria, J.; Pardo, E.; Armentano, D.; Jansen, C.J. Gas Transport in Mixed Matrix Membranes: Two Methods for Time Lag Determination. Computation 2020, 8, 28. [CrossRef]

(C) 2020 by the authors. Licensee MDPI, Basel, Switzerland. This article is an open access article distributed under the terms and conditions of the Creative Commons Attribution (CC BY) license (http://creativecommons.org/licenses/by/4.0/). 